\title{
REINVENTANDO A FORMAÇÃO DOCENTE: UMA EXPERIÊNCIA DEMOCRÁTICA E EMANCIPATÓRIA NA EDUCAÇÃO PÚBLICA
}

\author{
Maurício Cesar Vitória FAGUNDES ${ }^{\mathrm{i}}$ \\ Elisa Daniele de ANDRADE ${ }^{\text {ii }}$
}

\begin{abstract}
RESUMO
Este artigo coloca em tela um processo de formação continuada desenvolvido com docentes, com membros dos Conselhos Escolares e aberto à comunidade escolar de nove Unidades Educacionais do Campo do município de Araucária - estado do Paraná, Brasil. O objetivo principal deste artigo é discutir as possibilidades ou provocações que podem ser geradas por um processo de formação, que sinaliza a intencionalidade na implementação e/ou avanço da democratização da Educação do Campo. A metodologia utilizada foi uma pesquisa de base qualitativa, referenciada na pesquisa participante, utilizando para a coleta de dados grupos de discussões, observação participante e complementada pela análise documental. O registro para posterior sistematização foi por meio do diário de campo. Este estudo teve como principais aportes teóricos Freire (1996, 1979), Lima (2010), Marcelo (2010), Paro (2016) e Brandão (1993). Como resultado deste estudo, foi possível perceber a necessidade da ampliação da oferta de formação continuada específica para a Educação do Campo. Também se percebeu que, de forma coletiva, os docentes redescobrem o poder e a capacidade profissional de realizar e propor outro tipo de formação, como também propor condições objetivas para o exercício profissional docente, refletindo a assunção de uma postura democrática na direção da emancipação humana.
\end{abstract}

PALAVRAS-CHAVE: Formação continuada; Gestão democrática; Pesquisa participante.

\section{REINVENTING TEACHER TRAINING: A DEMOCRATIC AND EMANCIPATORY EXPERIENCE IN PUBLIC EDUCATION}

\begin{abstract}
This article presents the development of a lifelong learning program developed with the participation of teachers, with members of School Councils and the wide school community of nine Field Education Units in the township of Araucária, state of Paraná, Brazil. The main goal of this article is to discuss the possibilities or provocations that can be created by a training process, which signalizes an intentionality in the implementation and/or advancement of democratization in Field Education. The methodology used consisted of qualitative research, based on the method of participant research, with the aim of gathering data on discussion groups and performing participant observation. This process
\end{abstract}

\footnotetext{
${ }^{\text {i }}$ Doutor em Educação pela Universidade do Vale do Rio dos Sinos - UNISINOS. Professor Associado da Universidade Federal do Paraná -Setor Litoral - UFPR Litoral. Docente do Programa de Pós-Graduação em Educação: Teoria e Prática de Ensino - Mestrado Profissional e Docente do Mestrado Profissional em Rede Nacional para Ensino das Ciências Ambientais. Coordenador do Grupo de Pesquisa Universidade Escola. Email: mauriciovitoriafagundes@gmail.com.

ii Mestranda no Programa de Pós-graduação em Rede Nacional em Ciências Ambientais. Atualmente é Coordenadora da Educação do Campo da Secretaria Municipal de Educação de Araucária-PR. Membro do Grupo de Pesquisa Universidade Escola. E-mail: elisa.andrade@educacao.araucaria.pr.gov.br.
} 
was complemented by document analysis, and field diaries were written during the research, to be used in a posterior systematization. The main theoretical basis of this study was grounded in Freire (1996, 1979), Lima (2010), Marcelo (2010), Paro (2016) and Brandão (1993). The main result of the research was the discovery of a need for more lifelong learning programs directed toward Field Education. It was also found that, in these activities, teachers collectively rediscover their power and professional capability of performing and proposing another kind of training. Additionally, they were able to propose objective conditions for a professional teaching performance, reflecting the taking of a democratic stance toward human emancipation.

KEYWORDS: Lifelong learning; Democratic management; Participant research.

\title{
REINVENTANDO LA FORMACIÓN DOCENTE: UNA EXPERIENCIA DEMOCRÁTICA Y EMANCIPATORIA EN LA EDUCACIÓN PÚBLICA
}

\begin{abstract}
RESUMEN
Este artículo pone en tela un proceso de formación continuada desarrollado con docentes, con miembros de los Consejos Escolares y abierto a la comunidad escolar de nueve Unidades Educativas del Campo del municipio de Araucária estado de Paraná, Brasil. El objetivo principal de este artículo es discutir las posibilidades o provocaciones que pueden ser generadas por un proceso de formación, que señala la intencionalidad en la implementación y / o avance de la democratización de la Educación del Campo. La metodología utilizada fue una investigación de base cualitativa, referenciada en la investigación participante, utilizando para la recolección de datos grupos de discusiones, observación participante y complementada por el análisis documental. El registro para posterior sistematización fue por medio del diario de campo. Este estudio tuvo como principales aportes teóricos Freire (1996, 1979), Lima (2010), Marcelo (2010), Paro (2016) y Brandão (1993). Como resultado de este estudio, fue posible percibir la necesidad de la ampliación de la oferta de formación continuada específica para la Educación del Campo. También se percibió que, de forma colectiva, los docentes redescubren el poder y la capacidad profesional de realizar y proponer otro tipo de formación, así como proponer condiciones objetivas para el ejercicio profesional docente, reflejando la asunción de una postura democrática en la dirección de la emancipación humana.
\end{abstract}

PALABRAS CLAVE: Formación continua; Gestión democrática; Investigación participante.

\section{INTRODUÇÃO}

Muitos são os debates que envolvem a educação e, em sua maioria, esta é apontada como a grande culpada ou a grande "salvadora", sendo responsabilizada tanto pelas mazelas quanto como o grande fator de mudança social, geradora de uma melhor qualidade de vida. Mas o que é a educação senão um processo feito, essencialmente, por pessoas, imbricadas em contextos econômicos, sociais, políticos, regionais-global, entre outros? A tessitura dessas relações passa a constituir a educação, a escola e o que fazemos, ou o que não queremos mais fazer nesse espaço. 
De forma geral, nosso atual contexto revela uma escola submetida a políticas regulatórias e avaliações de larga escala, com fortes marcas neoliberais, que insistem na padronização da formação, desconsiderando as realidades locais e os saberes populares.

A forma de resistência e tensionamento desse processo passa pelo envolvimento e pela problematização dos sujeitos em seus espaços de criação de vida e de estudo, frente ao projeto de sociedade que lhes é imposto.

Neste artigo, defendemos que um dos caminhos possíveis para o enfrentamento e superação dessa condição macro, imposta à educação, passa pela gestão escolar democrática como princípio educativo e de métodos democráticos para efetivá-la. Nessa senda, vislumbramos nas relações efetivadas pelo diálogo freireano e pela participação um horizonte para a construção de um processo educativo que tencione a emancipação humana.

A pesquisa que gerou este estudo teve como referência um curso de Especialização em Gestão e Processos em Educação, que desenvolveu na segunda fase, um processo de formação docente por um período de 160 horas, como um exercício de prática docente na concepção da multiplicação, em que as cursistas assumiam a responsabilidade social e política de socializar os conhecimentos por meio de um curso de extensão. Os sujeitos constituintes deste estudo são docentes, membros de conselhos escolares e comunidade escolar das Unidades Educacionais do Campo, do município de Araucária.

Ao problematizarmos a formação docente, temos por objetivo principal, neste artigo, compreender quais possibilidades e/ou provocações podem ser geradas por um processo de formação que tencione a democratização da Educação do Campo. As descobertas evidenciadas advêm da análise dos registros gerados, a partir da sistematização dos diálogos realizados com as comunidades escolares das Unidades Educacionais do Campo e da análise das propostas decorrentes da formação realizada.

A metodologia privilegiou a pesquisa qualitativa, com acento na pesquisa participante, utilizando como recursos para a coleta de dados a observação participante e a formação de grupos de estudos e discussão. Serviu-se, também, da análise documental, incluindo nesse bojo as produções dos participantes. Os dados foram estudados e interpretados por meio da análise de conteúdo, fundamentada na dialética, respeitada a inspiração etnográfica, que inclui olhar o fenômeno estudado na sua inserção social, temporal, política e cultural. Para tal, foram 
referências Brandão (1981, 2012, 2017, 2003), Freire (1981, 1996, 1987, 1986, 2010, 2009), Triviños (1987), Bauer e Gaskell (2002) e Bardin (1977).

A redação deste artigo assumiu o gênero feminino em respeito a maioria das participantes desta pesquisa, embora reconheça que a norma culta faça outros encaminhamentos.

O texto que segue está constituído de uma breve contextualização do campo de pesquisa e de seus sujeitos, um aporte conceitual sobre a Educação do Campo, Gestão Democrática e Formação Continuada, a análise dos resultados, findando com as considerações provisórias.

\section{BREVE CONTEXTUALIZAÇÃO DO CAMPO DE PESQUISA E SEUS SUJEITOS}

O campo pesquisado originou-se de uma formação continuada, desencadeada por meio de um curso de pós-graduação lato sensu com um currículo organizado com grandes temas como possibilidade de problematização das realidades das cursistas para estreitar o diálogo com o conhecimento sistematizado. Fundamentando-se nos conceitos de intelectual orgânico gramsciano e na educação popular freireana, na perspectiva da multiplicação, a proposta do curso assumia o compromisso político com a socialização e espraiamento dos conhecimentos, com o desafio de reinventá-los no momento da multiplicação, a partir das novas realidades.

O curso pesquisado se organizava em duas fases. A primeira, com uma carga horária de 200 horas aulas, se caracterizava pela fundamentação teórico-metodológica com aporte nas distintas realidades das cursistas. A segunda fase se constituía em um duplo desafio: da multiplicação e da pesquisa. Nela, cada cursista assumia o compromisso social e político de multiplicar os conhecimentos construídos na primeira fase, porém a partir da realidade de seu lugar. A multiplicação deveria ser organizada por cada cursista com um grupo de 15 professoras e ou pessoas da comunidade escolar, de modo a construir círculos de discussão sobre as temáticas estudadas na primeira fase.

Paralelo a esse processo, as cursistas organizavam suas pesquisas sobre o processo de multiplicação, como fonte para produção de seus trabalhos de conclusão de curso. Essa segunda fase, para as novas cursistas que se somavam, tinha o caráter de um curso de extensão, com carga horária de 160 horas de atividades. A proposta era que o curso de 
extensão e a pesquisa se desenvolvessem a partir dos fundamentos da metodologia da pesquisa participante, fundamentada em Brandão (1981, 2006).

Integravam o Curso de Especialização 50 professoras da rede pública, municipal e estadual, de três cidades: Paranaguá, Cerro Azul e Araucária. O recorte, aqui exposto, se propõe a analisar os documentos e encaminhamentos resultantes do diálogo estabelecido no grupo de estudos sobre Educação do Campo de Araucária. Esse grupo constituiu-se a partir dos encaminhamentos propostos no Módulo Gestão da Educação do Campo, tendo como sujeitos parceiras e, ao mesmo tempo pesquisadas, as profissionais da educação, membros dos conselhos escolares e comunidade escolar das Unidades Educacionais do Campo do município de Araucária.

A proposta de formação do grupo de estudos foi apresentada pelo coletivo de cursistas da Especialização, a partir do debate estabelecido sobre Educação do Campo, como uma estratégia para manter o diálogo permanente sobre a temática, objetivando traçar estratégias e definir encaminhamentos possíveis que permitissem, gradativamente, a implementação de ações voltadas para a melhoria da oferta da Educação do Campo em Araucária.

A pesquisa foi desenvolvida com os 116 (cento e dezesseis) concluintes do processo de formação e a análise foi construída a partir dos registros nos diários de campo, realizados após debates sobre a Educação do Campo no referido município. Esses registros resultaram dos encaminhamentos propostos durante o processo de formação continuada e culminaram na elaboração de tramas conceituais que apontavam reflexões e sugestões para avanços e melhorias na oferta da educação do campo em Araucária.

\section{EDUCAÇÃO DO CAMPO E A GESTÃO DEMOCRÁTICA}

É inegável que a educação assume um papel fundamental no processo de emancipação humana. As práticas pedagógicas desenvolvidas, tanto podem assumir um caráter de educação bancária, como Paulo Freire (1987) denominou as práticas caracterizadas por assemelhar-se com um procedimento bancário, em que a educação é meramente um depósito de conhecimento e as estudantes são como contas para esse depósito, passivos, sem protagonismo, ou, ao contrário, podemos ter uma postura educativa que se proponha caminhar na direção da emancipação. 
Nessa última perspectiva, a emancipação da qual se trata é a emancipação humana, em que as profissionais que nela atuam são fundamentais na mediação de práticas pedagógicas aportadas na realidade, como caminho para estimular a consciência crítica e a autonomia. Nesse sentido, a formação continuada assume um papel fundamental no processo educativo, proporcionando condições para que essas profissionais reflitam sobre as suas práticas no diálogo e no tensionamento com a realidade concreta, de modo a construir fazeres e pensares pedagógicos com os princípios da emancipação humana.

A Educação do Campo, conforme Caldart (2002), se caracteriza e se identifica pelos seus sujeitos. O campo, como espaço geográfico, está repleto de manifestações culturais específicas, que caracterizam os sujeitos que moram, trabalham, estudam, enfim, estabelecem suas relações e interações sociais nesse espaço, construindo sua identidade cultural.

A educação do campo se identifica pelos seus sujeitos: é preciso compreender que por trás da indicação geográfica e da frieza de dados estatísticos está uma parte do povo brasileiro que vive neste lugar e desde as relações sociais específicas que compõem a vida no e do campo, em suas diferentes identidades e em sua identidade comum;... A perspectiva da educação do campo é exatamente a de educar este povo, estas pessoas que trabalham no campo, para que se articulem, se organizem e assumam a condição de sujeitos da direção de seu destino (CALDART, 2002, p. 18).

Na mesma direção apontada por Caldart (2002), temos no texto da Lei de Diretrizes e Bases - LDB, Lei $n^{\circ}$ 9.394/96, em seu artigo 28, o reconhecimento da especificidade e do direito a uma educação diferenciada para os sujeitos do campo, o qual é um passo importante para a superação da lógica educacional excludente em que os sujeitos são tratados como aculturados e sem potencial para se apropriar de conhecimentos científicos.

Paulo Freire (1996) destaca que o processo pedagógico precisa valorizar, respeitar e estar articulado ao contexto sociocultural dos sujeitos envolvidos na prática educativa, cabendo promover uma ação voltada para a emancipação dos sujeitos, calcada na superação das situações de opressão. No que tange ao processo pedagógico, o autor é enfático ao afirmar que se as educadoras têm clareza de que não desejam assumir uma educação bancária, tornase fundamental que desenvolvam a sensibilidade do exercício de apreender, permanentemente, como os grupos populares com que trabalham e leiam as situações do mundo "que fazem de seu contexto imediato e do maior de que o seu é parte" (FREIRE, 1996, p. 32). Ou seja, aprender com eles e apreender deles seus conhecimentos populares, sua 
cultura e suas experiências, de modo a conectar com os novos conhecimentos que fazem parte do percurso formativo.

Portanto, faz-se necessário construir uma Educação do Campo que contemple as particularidades e singularidades dos sujeitos que produzem suas vidas no campo, superando o caráter reducionista de conteúdos e de práticas pedagógicas baseadas em estereótipos construídos historicamente sobre esses sujeitos.

Em Araucária, município lócus da pesquisa que origina este artigo, a Educação no Campo, denominada ainda de Educação Rural, tem seus registros iniciais na década de 1920, com um total de 20 escolas isoladas, unidocentes e multisseriadas. Na época, o município assumia feições estritamente rurais. Nas duas décadas seguintes, houve uma ampliação do número de escolas, chegando, aproximadamente, a 40 escolas isoladas. A partir da década de 1970, com a instalação de um polo industrial, houve mudança do perfil do Município, de rural para urbano, fato que também alterou o cenário da educação municipal. Entre os anos de 1991 e 2000, a gestão municipal promoveu um processo chamado "consolidação" de escolas rurais. De acordo com a Coleção História de Araucária (1997, p. 94), com o processo de consolidação as alunas das 21 escolas, distribuídas em localidades menores, foram reunidas em três escolas de maior porte.

Atualmente, na Rede Municipal de Educação de Araucária, a Educação do Campo compreende nove Unidades Educacionais - seis Escolas do Ensino Fundamental, que atendem, aproximadamente, 1.200 estudantes, e três Centros Municipais de Educação Infantil, que atendem, aproximadamente, 250 crianças.

A trajetória dessas escolas do campo, no que se refere à base legal nacional, apresentam uma boa sintonia conceitual acerca da temática da gestão democrática. A presença dessa temática, mesmo que no aspecto documental, facilitou o diálogo estabelecido no referido processo de formação continuada, no qual o desafio era a construção ou reconstrução coletiva e democrática de conhecimentos, com o objetivo de melhor compreender para assim superar os desafios presentes na Educação do Campo.

Nessa direção, destaca-se o Plano Nacional de Educação - PNE (2014) como base legal e, em seguida, o exercício efetivo da gestão democrática na rede municipal. O PNE na Meta 19 trata de mecanismos para efetivação da gestão democrática da educação, apontando na estratégia 19.5 a implantação e/ou fortalecimento de Conselhos de Educação nos 
municípios e de Conselhos Escolares nas Unidades Educacionais, com representatividade de todos os segmentos da comunidade escolar e local, sendo de responsabilidade dos sistemas de ensino viabilizar a implantação desses e de outros mecanismos que promovam a gestão educacional democrática e participativa.

A mobilização das profissionais da educação e da comunidade escolar no município de Araucária precedeu em dez anos, em relação ao PNE, a implantação de um Conselho Municipal de Educação com a criação da Lei Municipal $n^{\circ} 1.528 / 2004$, que instituiu o Sistema Municipal de Ensino. Uma trajetória participativa e atuante que reflete a consciência que os profissionais da rede municipal de educação têm sobre a importância do princípio da gestão democrática na efetivação de uma proposta de educação emancipatória.

No ano de 2012, foram publicadas as Diretrizes Municipais de Araucária, documento que referencia os encaminhamentos da rede municipal de educação. Esse documento aponta como um dos princípios orientadores do processo educacional a Gestão Democrática, como pressuposto da promoção de uma educação de boa qualidade, atendendo aos interesses da sociedade, garantindo o acesso, a permanência e o aprendizado de todos, com equidade. Defende, ainda, “ações colegiadas transparentes e autônomas” (DME, 2012, p. 31).

Entende-se que a gestão democrática vai muito além da implementação de mecanismos que a promovam seus princípios no âmbito documental. A efetivação de uma gestão educacional democrática requer ações de fortalecimento desses mecanismos, pautandoos no diálogo e na alteridade.

\section{FORMAÇÃO CONTINUADA}

Uma das ferramentas possíveis para o fortalecimento da gestão democrática é o processo de formação continuada, quando promovido na perspectiva dialógica com vistas à transformação da realidade e dos próprios sujeitos envolvidos na prática pedagógica. $\mathrm{O}$ conceito de diálogo fundante dessa formação era inspirado em Freire (2003), destacando elementos como: respeito aos saberes das educandas, escuta respeitosa, expressão da liberdade de fala e de escuta de pessoas livres e em processo de constante libertação, geradora de debates e problematizações, que revelam a visão e a postura política da educação, a qual, ao mesmo tempo em que denuncia a opressão real também educa para sua transformação. 
Assim, o diálogo como instrumento da formação e ao mesmo tempo da conscientização, expressão política do sujeito que faz história.

O processo de aprendizagem nos acompanha desde a mais tenra idade, se prolongando até a morte, perspectiva assumida por Freire (1996) ao afirmar que como seres humanos somos inconclusos e, portanto, em constante processo de aprendizagem. Esse pressuposto freireano se aplica a todas envolvidas com processos educativos, mas, com maior ênfase, às profissionais da educação.

Se o nosso horizonte é a construção de uma sociedade democrática e se a escola tanto é parte como se constitui nas relações desenvolvidas em sociedade, é imperioso que sejam desenvolvidos mais do que discursos em nossas escolas, mas sim, práticas democráticas. A partir da percepção de Lima (2010, p. 18)

[...] são os professores profissionais essenciais para alcançar-se a democratização do ensino: ao ensinar o conhecimento produzido historicamente, ao não excluir exercendo junto aos estudantes a experiência do respeito, da convivência harmônica, que desenvolva capacidades como as de pensar, refletir e que mantenham sua dignidade.

São muitos os desafios que a educação precisa superar para, progressivamente, alcançar mudanças efetivas no processo educacional. Desafios esses que, em sua maioria, estão diretamente relacionados ao maior investimento público na educação, perpassando desde a infraestrutura adequada das unidades até, e especialmente, a valorização profissional e condições adequadas de trabalho. Dentre tantos investimentos necessários, destaca-se a importância da oferta de formação continuada como um dos aspectos de valorização profissional, conforme cita Lima (2010, p. 44).

[...] a qualidade da educação passa pela valorização profissional, que passa por sua vez, pela formação do professor. E para tanto, se faz necessário que a qualidade da formação caminhe paralelamente à conquista da universalidade do acesso à escola pública, em especial ao que diz respeito à população que historicamente tem feito parte dos segmentos da sociedade onde ainda é acentuada a exclusão social.

Outro aspecto que nos remete à importância da oferta de formação continuada está relacionado à formação inicial. O paradigma tradicional de educação tem construído processos educacionais fragmentados e hierarquizados. Nas universidades, normalmente, a formação, segue um currículo estanque, havendo pouco planejamento coletivo, em que as 
professoras são lotadas em departamentos por áreas de conhecimentos e pouco sabem dos projetos pedagógicos dos cursos e das realidades das estudantes com quem trabalham.

Essa estrutura reflete na formação inicial para a docência, visto que a separação da extensão, do ensino e da pesquisa é decorrente do fato de serem gestados por pessoas diferentes e em espaços distintos, ficando a cargo das estudantes tentarem desfragmentar a já fragmentada formação (FAGUNDES, 2019). Essas lacunas ficam mais evidentes ainda quando a professora, recém-formada adentra na escola de Educação Básica e se depara com a reprodução ampliada das lacunas de sua formação, ou seja, currículos engessados, turmas numerosas, falta de estrutura, baixos salários, horário escolar fragmentado, falta de tempo para planejar individual e coletivamente, entre outras.

A partir desse contexto, a formação continuada adquire um papel muito importante: o de fundamentar e problematizar a prática docente em uma perspectiva crítica e de totalidade, situada no tempo e no espaço. Por vezes, esse espaço da formação continuada é apenas pontual, mas, em algumas situações, assume o papel de re-formar a formação.

Talvez por reconhecer essas necessidades, a formação continuada está indicada na legislação, em todas as esferas de governo (federal, estadual e municipal). No âmbito nacional, podemos destacar a LDB, no artigo 62 e em seu $\S 1^{\circ}$, quando indica a responsabilidade da esfera pública no processo de formação, seja ele inicial ou continuado, dos profissionais do magistério.

Art. 62. A formação de docentes para atuar na educação básica far-se-á em nível superior, em curso de licenciatura plena, admitida, como formação mínima para o exercício do magistério na educação infantil e nos cinco primeiros anos do ensino fundamental, a oferecida em nível médio, na modalidade normal. (Redação dada pela Lei $n^{\circ} 13.415$, de 2017) $\S 1^{\circ} \mathrm{A}$ União, o Distrito Federal, os Estados e os Municípios, em regime de colaboração, deverão promover a formação inicial, a continuada e a capacitação dos profissionais de magistério (Incluído pela Lei $\mathrm{n}^{\circ} 12.056$, de 2009).

Outro documento que merece destaque, no que se refere a indicativos sobre a formação continuada, é o Plano Nacional de Educação. A Meta 16 do PNE estabelece que, em regime de colaboração, a União, os Estados e os Municípios devem promover o processo de formação continuada aos profissionais do magistério, respeitando as especificidades de cada sistema de ensino. 
Meta 16: formar, em nível de pós-graduação, $50 \%$ (cinquenta por cento) dos professores da educação básica, até o último ano de vigência deste PNE, e garantir a todos (as) os (as) profissionais da educação básica formação continuada em sua área de atuação, considerando as necessidades, demandas e contextualizações dos sistemas de ensino (PNE, 2014).

No município de Araucária, lócus desta pesquisa, a formação continuada está pautada nos princípios presentes nas Diretrizes Municipais de Educação - DME. De acordo com esse documento, o processo de formação continuada dos profissionais da rede municipal de educação tem como objetivo "contribuir para que estes profissionais ampliem a compreensão da realidade de seu tempo, de forma que favoreça a humanização de si e do seu trabalho, bem como sua autonomia" (DME, 2012, p. 53).

As diretrizes ressaltam, ainda, que a formação continuada "deve ser realizada em momentos periódicos de estudo, reflexão, planejamento e avaliação, de modo a garantir a reflexão sobre a prática educacional e a busca de aperfeiçoamento técnico, político e ético" (DME, 2012, p. 53).

Também no Plano Municipal de Educação - PME de Araucária, homologado pela Lei Municipal $n^{0} 2.848 / 2015$, sua Meta 14 dispõe sobre os objetivos da formação continuada disponibilizada aos profisssionais que atuam na rede municipal de educação.

Meta 14 - Organizar um plano de formação continuada, que promova a qualificação profissional através de reflexão teórico-prática, possibilitando a incorporação/ produção de novos conhecimentos científicos e tecnológicos na área educacional (PME, 2015).

Atualmente, no Município, 20\% da carga horária semanal das professoras é destinado a atividades formativas ofertadas pela Secretaria Municipal de Educação - SMED. A formação continuada é organizada conforme os grupos que atuam com cada ano escolar e/ou disciplina, sendo encaminhada pela equipe interna da SMED e/ou a partir de parcerias firmadas com instituições educacionais de ensino superior.

\section{A PROPOSTA DE FORMAÇÃO CONTINUADA ANALISADA}

Considerando a importância de tratar das especificidades da Educação do Campo no processo de formação continuada dos profissionais da educação e a importância da participação da comunidade escolar no processo de gestão das Unidades Educacionais, em 
2018, a Secretaria Municipal de Araucária, em parceria com a Universidade Federal do Paraná - UFPR, ofertou às profissionais e comunidade escolar, em geral, das Unidades Educacionais do Campo o curso de extensão universitária Gestão de Processos Educacionais, Diversidade e Inclusão - GPEDI.

O curso de extensão foi organizado e ministrado pelas 10 (dez) cursistas da Especialização em Gestão de Processos Educacionais, Diversidade e Inclusão - GPEDI, sob a orientação das professoras da UFPR. As cursistas da especialização, que assumiram o papel de multiplicadoras no curso de extensão, são professoras ou pedagogas da rede municipal e atuam, diretamente, com a Educação do Campo no Município, seja nas Unidades Educacionais do Campo ou na SMED, ocupando funções de coordenação.

O curso de extensão organizou-se em quatro módulos: Gestão Democrática e Educação Popular, Educação Inclusiva, Educação do Campo e Educação da Infância. Cada módulo com 40 horas, totalizando 160 horas de curso.

A metodologia utilizada para o curso compreendia encontros presenciais em hora/atividade das docentes cursistas, com atividades a distância, seminários, atividades com a comunidade local, mostra de trabalhos e relatório.

Os encontros presenciais, em hora atividade, consistiam em momentos de estudos e diálogos sobre as temáticas de cada módulo do curso. Nos intervalos entre os encontros presenciais foi proposta a realização de pesquisas sobre a realidade da comunidade escolar, objetivando aproximar as reflexões e fundamentação teórica em relação às práticas vivenciadas. Outra prática realizada pelas professoras multiplicadoras foi a mediação in loco, com realização de visitas às Unidades Educacionais, no intuito de esclarecer dúvidas, acompanhar e contribuir com os encaminhamentos das professoras cursistas.

Os principais objetivos dos seminários realizados foi promover a integração comunidade/escola e valorização do conhecimento e cultura da comunidade local, fazendo um resgate da identidade dos sujeitos que vivem e fazem suas vidas no campo. Os eventos foram estruturados para que sua programação, além da parte acadêmica, incluindo palestras relacionadas às temáticas dos módulos do Curso, contasse com a divulgação e comercialização de produtos da região, apresentações culturais de artistas da comunidade, resgate da história local com exposições e relatos de moradores, confraternização com café e almoço comunitário. 
As conferências locais tiveram como principal objetivo o estímulo a movimentos de integração da comunidade com a escola e um exercício de escuta, na perspectiva da gestão democrática. As docentes cursistas foram incentivadas a promover, com sua comunidade escolar, um diálogo sobre uma das temáticas do Curso, tendo como critério para seleção do tema considerar aquele que estivesse mais próximo da necessidade evidenciada na Unidade Educacional.

Considerando a importância da sistematização e registro das vivências, resultados, desafios, impressões e perspectivas, uma proposição feita às docentes cursistas foi a elaboração de um relatório sobre o curso de extensão, em que constasse a narrativa da trajetória pessoal no curso, as impressões, limites, superações e sugestões.

No objetivo de promover a socialização das práticas pedagógicas desenvolvidas durante o período do Curso, para o último seminário local, as docentes cursistas das nove Unidades Educacionais foram convidadas a expor alguns trabalhos desenvolvidos com suas turmas. Trabalhos esses que refletiram, especialmente, a busca pelo resgate da identidade e da valorização dos sujeitos do campo.

Os encaminhamentos propostos, em todos os módulos, foram direcionados para o contexto da Educação do Campo, propondo pesquisas e reflexões sobre as temáticas pautadas na realidade vivenciada pelas profissionais, pelas crianças, pelas estudantes e pelas comunidades da escola e de seu entorno.

Na perspectiva da escuta e do entendimento de que o diálogo é fundamental para reconhecer a realidade vivenciada pelos sujeitos envolvidos no processo educativo, especificamente no Módulo sobre Educação do Campo, uma das atividades propostas consistia na construção de uma trama conceitual com sugestões voltadas para a melhoria da Educação do Campo no Município.

As cursistas foram convidadas a registrar, fundamentadas nas discussões previamente realizadas, tanto nos momentos dos encontros presenciais do Curso, como no interior das Unidades Educacionais, sugestões ou indicações de propostas que atendessem as demandas evidenciadas na Educação do Campo em Araucária. A partir dos registros das discussões, as cursistas buscavam caminhos, por meio das políticas públicas sobre a formação continuada e destas com suas respectivas realidades. 
A atividade consistia em construir uma trama conceitual, fazendo a relação entre as ideias dos textos lidos, as discussões já realizadas em outros encontros presenciais e as sugestões levantadas no grupo para o cotidiano do trabalho pedagógico nas unidades do campo.

O grande tema gerador proposto foi Educação do Campo, tendo como eixos de desdobramento: "ser educador do campo", "Educação do Campo: identidade em construção" e "desafios para os educadores do campo", políticas públicas que garantam objetivamente o desenvolvimento das aulas no campo, como por exemplo o transporte escolar para os/as professores(as), bibliotecas com acervos que tratem de temas da Educação do Campo, adequação dos Projetos Políticos Pedagógicos à realidade do campo e formação continuada para atender a realidade das educadoras do campo.

Os debates que se desenvolveram abordaram muitas questões relacionadas às políticas públicas para a Educação do Campo. Ficou evidente nesse aspecto a ausência de discussões sobre essa temática em momentos anteriores de formação continuada. A grande maioria das presentes desconheciam legislações pertinentes à Educação do Campo, sejam elas de nível nacional ou local.

\section{DESCOBERTAS PARTEJAdas PElos díllogos E ANÁlise de DOCUMENTOS}

Os documentos produzidos pelos diálogos e pelas tramas conceituais resultaram no encaminhamento de um total de 122 sugestões propostas para a melhoria da qualidade da Educação do Campo em Araucária.

As temáticas mais recorrentes que compuseram as tramas conceituais foram: formação continuada e valorização profissional; valorização e respeito da identidade dos sujeitos do campo; infraestrutura; gestão escolar; e políticas públicas para a educação do campo municipal.

O Quadro 1 mostra a distribuição das propostas em dez agrupamentos, de acordo com a proximidade das temáticas apontadas durante as discussões, apresentações e na proposição escrita dos grupos. 
Quadro 1 - Agrupamento das proposições apresentadas para a Educação do Campo

\begin{tabular}{|l|c|}
\hline \multicolumn{1}{|c|}{$\begin{array}{c}\text { Temática na qual houve proposta } \\
\text { de ações para a Educação do Campo }\end{array}$} & $\begin{array}{c}\text { Quantidade de propostas } \\
\text { sobre a temática }\end{array}$ \\
\hline Identidade e valorização do campo & 41 \\
\hline Formação continuada & 21 \\
\hline Políticas públicas & 15 \\
\hline Infraestrutura & 10 \\
\hline Educação na perspectiva emancipatória & 9 \\
\hline Educação e meio ambiente & 6 \\
\hline Ensino-aprendizagem & 6 \\
\hline Recursos humanos & 6 \\
\hline Propostas intersetoriais & 5 \\
\hline Gestão escolar & 3 \\
\hline
\end{tabular}

Fonte: SMED Araucária (2018)

Ficou evidente, pela quantificação exposta, que as cursistas consideram essencial o respeito, o resgate e a valorização da identidade dos sujeitos do campo, incluindo essas características nas práticas pedagógicas. Constata-se, ainda, o reconhecimento da formação continuada como um mecanismo que pode garantir a manutenção das discussões sobre a Educação do Campo, tratando-a dentro de sua especificidade e não de forma genérica como ocorre, quando a formação ofertada não reconhece as singularidades do local de atuação dos profissionais.

O texto de uma das propostas construídas, a partir dessa formação, referia-se à construção de um grupo permanente de estudos e reflexão, visando o fortalecimento do coletivo de profissionais que atuam na Educação do Campo no Município e à efetivação de ações, em prol da melhoria dos serviços ofertados. Ou seja, reafirmação da importância da formação continuada de forma contextualizada e permanente.

\section{GRUPO DE ESTUDOS: CONSTITUIÇÃO DECORRENTE DA FORMAÇÃO CONTINUADA}


A solicitação para formação de um grupo de estudos foi acatada pelas responsáveis pela formação e, na última semana de formação, foi socializada com todas as cursistas a proposta de composição de um coletivo que aprofundasse os conhecimentos acerca da Educação do Campo. O convite para integração do grupo foi compartilhado com todas as participantes.

Tal encaminhamento deu-se como consolidação da ideia de que, como citado por Lima (2010), os processos democráticos são resultados de conquistas estabelecidas na luta do coletivo organizado.

É importante ressaltar, concordando com Sousa (2005), que em relação aos processos democráticos nada é dado e sim, fruto da conquista das profissionais envolvidas e comprometidas. Não seria diferente em relação à qualidade da educação e, portanto, às condições adequadas de trabalho (LIMA, 2010, p. 82).

Ao término da semana, o grupo foi formado com 31 pessoas, que atuam nas Unidades Educacionais do Campo e outros órgãos que manifestaram interesse em participar das sessões de estudo e discussão de temáticas de identificado interesse coletivo, corroborando a conceituação de formação permanente em Freire (1996), sustentada no entendimento de que somos seres inconclusos e, portanto, em eterna formação. Nessa compreensão, os encontros foram se constituindo, tendo o primeiro encontro do grupo contado com a participação de 12 pessoas.

No aludido encontro, foi definida a periodicidade mensal dos encontros do grupo e o objetivo geral, que era de fortalecer as discussões e o coletivo de profissionais que atuavam com a Educação do Campo no Município, com o intuito de formalizar encaminhamentos que pudessem trazer avanços e melhorias.

A primeira demanda do grupo foi a sistematização, no formato de um documento, das sugestões apresentadas pelas cursistas do GPEDI durante o encaminhamento da atividade da trama conceitual referente à Educação do Campo em Araucária. A reunião tratou, ainda, da organização dos textos apresentados pelas cursistas durante o processo de formação, objetivando a formatação de uma proposta de itens suleadores para os momentos de estudo.

Essa sistematização prévia possibilitou a formulação de 33 sugestões, que foram apresentadas e validadas no coletivo de profissionais, comunidade escolar e local, o que 
resultou na organização de um Seminário Local de Educação do Campo de Araucária, realizado em uma das comunidades do campo, denominada Rio Verde.

No segundo encontro, a pauta constou da estruturação de um texto com as sugestões resultantes da síntese prévia, realizada no primeiro encontro do grupo. O texto foi aperfeiçoado e o debate inicial do grupo se concentrou na definição de uma finalidade e uma meta. Além disso, ficou acertado que a finalidade do documento seria elencar as demandas apresentadas pelas comunidades escolares do campo, com o objetivo de subsidiar os encaminhamentos para a efetivação de políticas públicas, visando à melhoria contínua da Educação do Campo no Município. Na ocasião, ficou estabelecido, como meta do grupo de estudos, o trabalho em prol de proposições para "políticas públicas específicas que garantissem uma educação de qualidade à população do campo”.

Como resultado desse encontro, ficou visível a grande preocupação das profissionais cursistas com a garantia, assegurada pelo Município, do deslocamento para as Unidades Educacionais do Campo, uma vez que um percentual considerável das profissionais que trabalham no campo depende do transporte disponibilizado pela mantenedora para o chegar até o local de trabalho. Na realidade observada, esse serviço não está regulamentado, de modo que todo início de ano letivo as profissionais convivem com a incerteza de dispor ou não do serviço, ocasionando, inclusive, a desistência de algumas profissionais em optar pelas vagas existentes nas Unidades Educacionais do Campo.

Destacam-se algumas falas dessas profissionais sobre essa reivindicação: "Subsidiar o acesso do profissional a sua unidade" (Professora A); "Priorizar que as profissionais que residem no campo possam atuar na Educação do Campo, possibilitando-lhes acesso às unidades de ensino" (Professora B).

Esse ponto foi o que levantou maior interesse e preocupação do grupo, que acabou por ser o definidor da continuidade do estudo sobre a temática, deixando visível a percepção das cursistas de que a formação docente está imbricada com a formação e atuação profissional, no que diz respeito aos direitos da profissão e às condições objetivas de trabalho. $O$ grupo entendeu que, mais do que ser discutido todo início de ano, havia a necessidade de normatizar ou legalizar seus direitos.

Dos debates promovidos, o encaminhamento resultante foi a elaboração de um parecer e um projeto de lei para garantir e regulamentar a viabilização do acesso às Unidades $======$ 
Educacionais. No entanto, durante a discussão, foi pontuado outro item relacionado ao assunto: subsidiar financeiramente as profissionais que, devido à consolidação das escolas do campo, embora morem no campo, precisam se deslocar por longas distâncias, até o local de trabalho. Aqui, ficou claro o processo de discussão da formação e profissionalidade docente, como defende Marcelo (2009).

Para realizar proposições acerca de sua profissionalidade docente, as professoras envolvidas nesse processo, sentiram a necessidade de molhar-se, de encharcar-se dessa realidade, como preconiza Freire (1979, p. 30), ao lembrar que é fundamental que possamos compreender a realidade para transformá-la, pois "quando o homem compreende a sua realidade, pode levantar hipóteses sobre o desafio dessa realidade e procurar soluções. Assim, pode transformá-la e o seu trabalho pode criar um mundo próprio, seu Eu e as suas circunstâncias".

Sendo assim, podemos destacar que, embora o movimento do grupo de estudos tenha tido o período de apenas um semestre, até a construção deste artigo, foi possível perceber a mobilização das docentes cursistas se apropriando de suas realidades e provocando um outro tipo de formação, de iniciativa pautada na perspectiva emancipatória que tende a se consolidar em um mecanismo de empoderamento e emancipação humana desse grupo de profissionais.

\section{CONSIDERAÇÕES PROVISÓRIAS QUE INSPIRAM OUTROS OLHARES E OUTROS TRABALHOS}

A formação docente continuada, de forma geral, é compreendida como importantíssima para a efetivação de uma prática pedagógica transformadora. Por meio da fala e das proposições explicitadas neste artigo, foi possível perceber que as docentes, quando provocadas a assumirem o protagonismo de suas formações, em um espaço democrático, desenvolveram posições críticas frente à educação, ao contexto e à profissão.

O movimento proposto de uma formação que as tornava multiplicadoras, ou seja, provocava-as à assunção de um papel social e político com seus pares e comunidade escolar, tirava-as da condição de espectadores. Em virtude de terem vivido, de forma majoritária, formações continuadas como alguém que apenas recebia ou sofria a formação, poderiam reagir e não aceitar tal proposição ou provocação. Na situação apresentada, pode-se constatar 
que o resultado foi o contrário, as pessoas mobilizaram-se para dar continuidade ao processo formativo.

A materialidade dessa mobilização foi a constituição do grupo de estudos e reflexão, com o objetivo de formalizar encaminhamentos que pudessem fortalecer e democratizar as discussões do coletivo de profissionais que atuam com a Educação do Campo municipal, buscando a mobilização e implementação de ações que beneficiassem a comunidade escolar e local das Unidades Educacionais do Campo.

Ficou evidente que essa ação não visava cumprir os processos demandados pela Secretaria de Educação do Município, para dar continuidade à formação docente, mas colocava à mesa descobertas daquilo que lhes fazia sentido, das necessidades e desejos profissionais de espaços ainda a serem ocupados. Em outras palavras, de forma coletiva descobriam seu poder e capacidade profissional de realizar e propor outro tipo de formação e também propor condições objetivas para o exercício profissional docente.

Nesse processo, ao eleger a realidade concreta como ponto de partida e retorno da formação, as cursistas, professoras que atuam e trabalham com a Educação do Campo, assumiram como essencial a manutenção e ampliação da formação continuada com ênfase nas especificidades da Educação do Campo, reconhecendo que esse espaço se consolida como um espaço de democratização e emancipação. As falas das professoras reforçam a importância desses momentos de formação quando destacam em suas proposições, que é necessário "garantir formação continuada aos profissionais do campo contemplando as especificidades da educação do campo" e "ter espaço permanente de debate".

Foi possível entender que o método e a metodologia dialógica da formação, que tencionou a democratização da educação, favoreceu a postura participativa das professoras cursistas, pois não se tratava de falar sobre processos democráticos, mas de um pensar-agir coletivo e democrático.

Por fim, embora seja este um processo de formação docente continuada, datado no tempo e no espaço, não é possível antever sua continuidade, mas podemos afirmar que o grupo de professoras cursistas saiu provocado e passou a provocar suas comunidades para práticas democráticas de educação, de ensino, de aprendizagem e de participação coletiva, refletindo uma postura na direção da emancipação humana. 


\section{REFERÊNCIAS}

ARAUCÁRIA (Município). Prefeitura Municipal. Secretaria Municipal de Cultura. Coleção História de Araucária. 1997.

ARAUCÁRIA (Município). Prefeitura Municipal. Secretaria Municipal de Educação.

Diretrizes Municipais de Educação. 2010.

ARAUCÁRIA (Município). Prefeitura Municipal. Secretaria Municipal de Educação. Plano Municipal de Educação. 2015.

BRASIL. Lei de Diretrizes e Bases da Educação Nacional. Lei no 9.394, de 20 de dezembro de 1996.

BRASIL. Lei $\mathbf{n}^{\mathbf{0}} \mathbf{1 3 . 0 0 5}$, de 25 de junho de 2014. Aprova o Plano Nacional de Educação PNE e dá outras providências. Brasília: MEC, 2014.

BRANDÃO, Carlos Rodrigues (Org.). Pesquisa participante. 3. ed. São Paulo: Brasiliense, 1983.

CALDART, Roseli Salete; CERIOLI, Paulo Ricardo; KOLLING, Edgar Jorge. Educação do Campo: identidade e políticas públicas. Brasília: Articulação Nacional por uma Educação do Campo, 2002.

CASASSUS, Juan. El precio de la evaluación estandarizada: la pérdida de calidad y la segmentación social. Revista Brasileira de Política e Administração da Educação, Porto Alegre, Anpae, v. 23, n. 1, p. 71-79, 2007.

FAGUNDES, Maurício Cesar Vitória et al. Gestão e Processos em Educação, Diversidade e Inclusão. Curitiba: UFPR Litoral, 2016.

FAGUNDES, Maurício Cesar Vitória. Repensando a formação docente. Curitiba: Anpae, 2019.

FREIRE, Paulo. Pedagogia da autonomia: saberes necessários à prática educativa. São Paulo: Paz e Terra, 1996.

FREIRE, Paulo. Educação e mudança. Rio de Janeiro: Paz e Terra, 1979.

FREIRE, Paulo. Educação como prática da liberdade. Rio de Janeiro: Paz e Terra, 2003.

LIMA, Jucimara Bengert. Formação continuada e desempenho estudantil: o caso de Araucária - Paraná. Curitiba, 2010.

MACHADO, Lucy Moreira. Formação continuada e gestão da educação: por uma política de qualificação. Curitiba: UTP, 2009. 
MARCELO, Carlos. Desenvolvimento profissional docente: passado e futuro. Sísifo. Revista de Ciências da Educação, v. 8, p. 7-22, 2009.

PARANÁ. Secretaria de Estado da Educação. Diretrizes Operacionais Estaduais de Educação do Campo. Curitiba: SEED/PR, 2010.

Recebido em: 18/06/2019

Aprovado em: 04/05/2020 